\title{
CRÓNICAS PORTUGUESAS DE LA GUERRA CIVIL DE ESPAÑA. LOS INFORMES DEL VICECÓNSUL PORTUGUÉS EN FERNANDO POO (14 DE AGOSTO - 31 DE OCTUBRE DE 1936)
}

\author{
Dr. D. Manuel Burgos Madroñero \\ Universidad de Málaga. España
}

\section{INTRODUCCIÓN}

"Deseando SS.MM. Católica y Fidelisima promover las ventajas del comercio de sus respecivos súbditos, las cuales pueden verificarse en el que reciprocamente hicieren de compra y venta de negros, sin ligarse a contratos y asientos perjudiciales, como los que en otro tiempo se hicieron con las Compañias Portuguesa, Francesa e Inglesa, los cuales fue preciso cortar o anular, se han convencido los dos altos Principes contrayentes en que, para lograr aquellos y otros fines y compensar de algún modo las cesiones, restituciones y renuncias hechas por la Corona de España en el Tratado preliminar de limites de $1^{\circ}$ de octubre de 1777 cederia S.M. Fidelisima, como de hecho ha cedido y cede, por si y en nombre de sus herederos y sucesores, a S.M. Católica y los suyos en la Corona de España, la isla de Annobón, en la costa de Africa, con todos los derechos, posesiones y acciones que tiene en la misma isla para que desde luego pertenezcan a los Dominios españoles del propio modo que hasta ahora ha pertenecido a los de la Corona de Portugal; y asimismo todo el derecho y acción que tiene o puede tener a la isla de Fernando del Pó, en el Golfo de Guinea, para que los vasallos de la Corona de España se puedan establecer en ella y negociar en los puertos y costas opuestas a la dicha isla, como son los puertos de Rio Gabón, de los Camerones, de Santo Domingo, de Cabo Formoso, y otros de aquel distrito, sin que por eso se impida o estorbe el comercio de los vasallos de Portugal, particularmente de las islas del Príncipe y de Santo Tomé, que al presente van y en lo futuro fueren a negociar en dicha costa y puertos, comportándose en ellos los vasallos españoles y portugueses con la más perfecta armonia, sin que por algún motivo o pretesto se perjudiquen o estorben unos a otros." (Art. 13 del Tratado del Pardo, 11 de Marzo de 1778). ${ }^{1}$

\footnotetext{
1 "Copia do Tratado que aprovó o Rey Católico qu'está escrito nas duas linguas". Caixa n. ${ }^{\circ}$. Arquivo Nacional da Torre du Tombo y Archivo General de Simancas, E. Legajo 7411 bis. folio6.
} 
Nunca se había firmado entre los dos Estados Ibéricos unos tratados mejores, que contentarán a ambas partes por igual y que más les convinieran. Si el Ministro Floridablanca: "lo único que quería era un refugio o agujero en las Costas de África" según la carta del Ministro de Negocios Extranjeros portugués, Ayres de Sa e Mello al entonces Embajador de España en Lisboa, Conde de Fernán Núñez ${ }^{2}$ y si el ambicioso malagueño don José Gálvez, Ministro de Indias, fundador y Presidente de la Real Compañía de Filipinas pensaba establecer alli una colonia mercantil por la utilidad que reportaría a su Compañía y a España, el tener una escala en sus viajes a Asia y sobre todo por la intención de ambos ministros de manumitirse y suplantar el monopolio que ingleses, franceses, holandeses, italianos y portugueses ejercían en el comercio de negros, con el cual se suministraba la mano de obra para el fomento de nuestros territorios americanos, no pudo ser mejor el resultado de dichos tratados.

El Ministro Gálvez llegaba a decir que "no imporlaría ceder a Portugal si preciso fuera, terrenos en Río Grande a cambio de Guinea y sobre todo si con esto se obtenía la plena neutralidad de Portugal en la guerra que ya se vislumbraba entre España e Inglaterra"'.

La inesperada muerte de Gálvez en 1787 y la caida de Floridablanca en 1792 impidió hacer realidad todos estos proyectos y fundamentalmente por la segunda guerra contra Inglaterra que inicia el rey español Carlos III, a la que apoya y se une su fiel aliada Portugal. No resultará extraño que España en esta circunstancia, tras el proceso revolucionario francés y la serie de acontecimientos que enumeramos a continuación olvide o no pueda atender a los territorios de Guinea.

En la llamada Guerra de las Naranjas de 1801, en la que ayuda a España la Francia revolucionaria, el Ministro de Carlos IV, don Manuel de Godoy, invade Portugal y ocupa la Plaza de Olivenza, que no se le devuelve, constituyendo actualmente "el Gibraltar portugués (Olivença)". Todos los proyectos de los Tratados de San Ildefonso y del Pardo se derrumban por la incapacidad y problemática de la política española de Carlos IV, la Revolución Francesa, la Invasión de España por las tropas napoleónicas, la ineptitud de Fernando VII, la Independencia de la América Española, el complicado reinado de Isabel II, el brevísimo de Amadeo de Saboya y la efimera Primera República Española.

Casi un "larguisimo" siglo después, en 1874, no vuelve la preocupación en España por aquellos territorios: se crea en Madrid la Real Sociedad Geográfica y surgen las primeras figuras defensoras del africanismo español, teóricos como Joaquín Costa y exploradores como Iradier, Osorio, Montes de Oca...

Abandondos hasta tal punto, que el famoso negrero malagueño Pedro Blanco en 1839 tuvo que denunciar al Gobierno Español la colonización de Fernando Poo por parte de Inglaterra, que había fundado un poblado (Clarence-City) en la isla de Fernando Poo con el

2 Archivo General de Simancas, E. Legajo 7411, folio 11.

3 Instrucción reservada de Don José Gálvez al Brigadier Conde de Argelejo, fechada en San Lorenzo el Real. 20 de octubre de 1777. Archivo General de Simancas E. Legajo 7411, folio 5. 
pretexto de establecer allí un Tribunal para la represión de la trata de negros y en esta politica de provocación, el Gobierno inglés llegó hasta ofrecer por la compra de Fernando Poo y Annobón 60.000 libras esterlinas.

Tras esta denuncia, el Gobierno de España envía un barco de guerra en 1843, el mando de Pinzón, que de nuevo se posesiona de las islas de Fernando Poo y Annobón, izando la bandera española. Seguramente, a Pedro Blanco no le movió afán patriotico alguno, sino que era la presencia inglesa en aquella zona, ya prohibida la trata de negros, la que molestaba a sus negocios; sus barracones e instalaciones del Río Gallinas fueron destruidos por el capitán inglés Denman en 1839.

Otra prueba más del abandono y desconocimiento de todo lo que ocurría en aquellos territorios, fue la propuesta que eleva el entonces Ministro de Marina y Ultramar, Dionisio Capaz, al Regente Baldomero Espartero, para que se le conceda a Pedro Blanco, por sus "méritos", el título de Intendente de la Marina Española, como asi fue. Adjunto el escrito del Ministro de Marina, que parece increíble:

"Serenisimo Señor: Cuando entre los graves cuidados para fomentar la Marina mercante y de guerra ofrece la penuria de erario, me ocupaba en calcula los medios de realizar el pensamiento altamente nacional e imporiante, de la colonización de las posesiones de Fernando Poo y Annobón, en términos que sirviendo de punto de partida para el comercio nacional con la costa de Africa, fuese también e depósito de negros que en la clase de libre y e virtud de convenios particulares pasasen a nuestra Antillas a reemplazar el déficit que ha de resulla precisamente de la estricta observancia de los tratados existentes sobre la abolición del tráfico de esclavos, he sido agradablemente sorprendido con un proyecto de propuesta, presentado por don Pedro Blanco, «sujeto a quien conozco» (el entrecomillado es mio) y que por sus relaciones, especiales conocimientos y bien adquirido concepto en el Comercio, tiene cuantas garantias pueden desearse, ofreciendo verificar la indicada colonización ya por si solo o asociandose, si le fuese necesario, a persona de su confianza, bajo cierlas bases y concesiones, en cuyo examen me ocupo.

Las cualidades de este individuo, que sobre sus circunstancias ya indicadas, reune la especial de haber residido por muchos años en la costa de Guinea, tener en ella grandes infuencias y poseer en la misma cuantiosos recursos hacen esperar que con su auxilio llegará a tener efecto este grandioso pensamiento; mas como en materia en si tan complicada han de ocurrir necesariamenie dificultades, la mayor parte locales; y como para vencerlas en aquel pais, podrá favorecer mucho, el que el sujeto ya alli conocido, se hallare revestido con alguna distinción del Gobierno, he pensado que podria ser politico y conducente a nuestro objeto, el concederle desde luego una distinción, que al paso que acredite en aquellas posesiones la confianza que se merece, le sirva al mismo de estimulo para continuar con constancia sus útiles tareas.

Por fortuna tiene a su favor, aún sin este motivo, señalados servicios que prestó en todas épocas, existiendo en mi poder comprobantes que acreditan haber recibido su educación facultativa en el Colegio de San Telmo de Málaga; haber hecho en La Habana y en la Peninsula servicios pecunarios y donativos para las urgencias del era- 
rio; haber defendido con las armas en la mano la causa nacional en el año de 1823. durante el sitio de Cádiz; y últimamente que acaba de hacer; a su costa, al referido Colegio de San Telmo, el voluntario y costoso obsequio de un uniforme completo de calle para todos los alumnos del mismo: circunstancias poco comunes, que vencen mi natural repugnancia a toda concesión que no sea rigurosamente de escala; y que me deciden a tener el honor de proponer a V.A. se digne agraciar al referido don Pedro Blanco con los honores de Intendente de Marina. Madrid, 28 de abril de 1843. Firmado: Dionisio Capaz. Serenisimo Señor".

Hay fechas claves en este nuevo sin vivir africanista de los españoles: 1884-1885, la Conferencia de Berlín en la que tiene la voz cantante la recién unificada Alemania y la astuta y diplomática Francia; alli se concretan las pretensiones al Camenún por parte alemana y de Gabón por parte francesa, olvidándose por completo los derechos que tenía España a estos territorios; 1898, cuando España, en esa caída libre hacia el abismo, pierde sus últimos territorios americanos, y teme que Estados Unidos desembarcara y se apoderara de sus territorios del Golfo de Guinera; finalmente, el año 1900, en el Tratado de Paris, tras un vergonzoso regateo por parte de Francia, España firma y acepta, que de los 200.000 kilómetros que debían corresponderle en la Guinea continental, queden estos reducidos a 22.000 kilometros cuadrados...

No obstante, desde 1874 a 1931, habian progresado, aunque no lo que debieran, los Territorios del Golfo de Guinea, en donde juegan la actuación del capitalismo español y extranjero, de las grandes companías maritimas, madereras y cultivadoras del cacao y del cafe, sin tener en cuenta la explotación laboral de los nativos.

Con la dictadura de Primo de Rivera (1925-1929) se crea la nueva Dirección General de Marruecos y Colonias y se producen esos gestos típicos de los dictadores mediterráneos cara el público: Eduardo González Gallarza (que después será Ministro de Franco), en la Navidad del año 1926, hace un espectacular y atrevido vuelo Melilla-Golfo de Guinea en un hidroavión, acción peligrosa y nada fácil en esa época, y en la Navidad de 1927, la escuadrilla Atlántica, con base en Valencia, repetirá el mismo vuelo desde Valencia a Guinea; por último la Exposición Iberoamericana de Sevilla, el año 1929, se construye un pabellón colonial dedicado al África Ecuatorial Española, que es muy visitado y elogiado.

Con la Segunda República, las maderas preciosas empiezan a rendir con las nuevas plantaciones y la producción, la atención y por primera vez mejoras sociales de aquellos territorios sigue creciendo. La actuación de la Segunda República responde perfectamente al esquema de colonización francesa, proponiéndose decididamente hacer rentable esas posiciones además de racionalizar y dignificar la ocupación españoal; entre los años 19321935, España importa de Guinea más de 40.000 millones de pesetas-oro, mientras exporta a Guinea tan sólo unos 4.000 millones; en el año 1935 se produce la división natural de los territorios de Guinea en dos distritos: Fernando Poo y las islas, que tendrán como capital

4 Burgos Madroñero, M.: "De negremo a Intendente de Marina: Pedro Blanco". Revista Jábega, Revista de la Diputación Provincial de Málaga, n. ${ }^{\circ} 66$, pp. 38-46. 
Santa Isabel; y por otra parte, la Guinea Continental, que tendrá como capital Bata. Administrativamente, existía como jefe supremo un Gobernador General en Santa Isabel y un Subgobernador en Bata. En cuanto a reformas y preocupación social, antes sólo en mano de misioneros, hombres y mujeres, se crea el Instituto Colonial Indígena, la Escuela Urbana de Bata con la finalidad de formar auxiliares para la Sanidad, la enseñanza y la administración.

En Fernando Poo, en 1936 existían dos periódicos, "La Guinea Española", que hace labor catequista, y "El Defensor de Guinea", de tipo colonial y atento a los negocios y que a partir de 1931 hace propaganda de la República y en febrero del 36 se convierte en portavoz del Frente Popular.

\section{LA GUERRA CIVIL EN LOS TERRITORIOS ESPAÑOLES DE GUINEA}

La rebelión militar de Julio de 1936, apenas causa inquietud alguna en aquellos territorios, en parte por la distancia y las confusas y pocas noticias que llegan a través de emisoras de radio extranjeras y sobre todo por existir una "entente" entre los partidarios del Frente Popular y la extrema derecha colonial ante el temor a la reacción de los nativos. En esos momentos, es Gobernador General de los Territorios de Guinea don Luis Sánchez Guerra, hijo del jefe político conservador de la desaparecida monarquía y hermano del que era entonces Secretario General de la Presidencia de la República y brazo derecho de Alcalá Zamora. Sánchez Guerra carecía de preparación especial para el desempeño de sus funciones, no se define ante la rebelión militar, se mantiene en dos aguas y solicita "misteriosamente" su dimisión, que según parece le fue concedida el 16 de septiembre; divulgada esta noticia, la noche del 18 al 19 de septiembre se produce un golpe militar incruento en Santa Isabel (Fernando Poo), realizado por el Teniente Coronel Serrano Moranges, quien se pone a las órdenes del Gobierno de Burgos.

Por el contrario, el Subgobernador de Bata, Miguel Hernández Porcel, sigue fiel al Gobierno de la República, y tiene que hacer frente a multitud de disturbios y desórdenes en el territorio de Río Muni, entre ellos, la marcha que organizan los madereros, partidarios del levantamiento militar sobre Bata, el 23 de septiembre, que fracasa; se afianza su dependencia de Madrid, apoyado primero por la marinería sublevada del crucero Méndez Núñez, fondeado en Bata, que acaba uniéndose al Frente Popular y tras expulsar a toda la of icialidad, partidaria de la rebelión militar, tras un accidentado viaje a la Península; otro barco, el Ciudad de Ibiza, que llega a Río Muni procedente de Barcelona con víveres y medicinas, cuya marinería está unida al Gobierno de Madrid enardece de nuevo los ánimos de los partidarios de la República en Río Muni, por último llega el buque mercante Fernando Poo, también fiel a la República, hecho que se preveía y sabían, produciéndose graves enfrentamientos y actos violentos.

Al amanecer del día 14 de octubre, procedente de Las Palmas, llega el barco Ciudad de Mahón, fletado y armado por los rebelados, con más de 500 hombres, cañones, ametralladoras, bombas... al Puerto de Bata, donde aún permanece el barco Fernando Poo, convertido en prisión de misioneros y otras personas de Río Muni; tras los avisos de rigor, el Ciudad 
de Mahón dispara dos cañonazos, que hacen impacto en la línea de flotación del Fernando Poo, momento en que militares del Ciudad de Mahón abordan el Fernando Poo, que acaba hundiéndose en poco tiempo, muriendo entonces algunos marineros del mismo y prisioneros del barco, e incluso militares del Ciudad de Mahón, que habian subido a bordo.

Tras esta actuación, huyen los supervivientes del Fernando Poo y los elementos más destacados que habian hecho de Ebibeyin su último reducto y multitud de familias pacíficas refugiándose en el Camerún y en Gabón, volviendo poco después la mayoría a Río Muni.

A las seis y media de la mañana del 15 de octubre, tras haber acabado y sometido a los partidarios del Gobierno de la República, se presenta el Ciudad de Mahón en Santa Isabel, dando por terminada su actuación en el continente. Acogido clamorosamente por sus habitantes se celebran actos militares y religiosos. La Guerra Civil se da por terminada en los territorios españoles del Golfo de Guinea. El Gobierno de Burgos designó nuevo Gobernador de Guinea al Capitán de Navío don Manuel Mendivil.

\section{LOS DOCUMENTOS}

En anteriores trabajos nos hemos ocupado de la Guerra Civil de España contada por Cónsules y Vicecónsules de Portugal. He podido comprobar la capacidad y lealtad a Salazar, además de un rigor histórico, no exento de crítica ante lo que ocurría en España. Los Cónsules portugueses profesionales, conscientes de su misión como Antonio de Cértima en Sevilla, Souza Pereira en Badajoz y Freitar Barjona de Tánger, dan prueba de su personalidad, incluso no demostrando en determinados momentos su simpatía por los sublevados.

Los informes de los vicecónsules en general son algo más flojos, dado que generalmente eran españoles, hasta cierto punto no comprometidos con Portugal, renunciando a dicha colaboración con Portugal y eligiendo el bando fiel a la República. No he podido averiguar las circunstancias personales de Juan Ramirez Dampierre, Vicecónsul español en Fernando Poo. Por supuesto que nunca escribe en portugués; sus escritos muestran descaradamente simpatía por el bando sublevado; debió ser un industrial o comerciante con influencia y poder alli en Fernando Poo, como delata de alguna manera su "sonoro" apellido.

Estos documentos se encuentran en el Arquivo do Ministerio de Negocios Estrangeiros de Lisboa Maço A8M2. Sin duda, faltan algunos documentos que por su importancia se enviarian a Salazar o sus ministros o bien no devueltos por algún funcionario e incluso seleccionados o escogidos para la colección de documentos publicados de los años 36 al 43 en nuevo volúmenes con el título genérico de "Dez Anos de Política Externa Portuguesa".

\section{N. B.:}

Hemos considerado no sólo interesante sino necesaria, acompañar esta comunicación de mapas y "cifras" para mejor esclarecimiento de lo expuesto:

- Situación Geográfica: estos territorios localizados en el Golfo de Guinea, están situados entre los $3^{\circ}$ de latitud N (isla de Fernando Poo, situada en el extremo $N$ ) y $2^{\circ}$ de latilud S (isla de Annobón, la más meridional y en Hemisferio Sur); longitud E $9^{\circ}-11^{\circ}$ del Meridiano de Greenwich. 
- Superficie: El total de las tierras que componen estos territorios, aproximadamente tienen una extensión de $27.000 \mathrm{~km}$, repartidos, también aproximadamente de la siguiente forma: Territorio Continental o Rio Muni, capital Bata, $22.000 \mathrm{~km}^{2}$ (aproximadamente la provincia de Badajoz). Territorios Insulares con Santa Isabel como capital de todos los territorios, situada en la Isla de Fernando Poo con $2.000 \mathrm{~km}^{2}$ aproximadamente (menos de la mitad de la isla de Mallorca), Annobón $18 \mathrm{~km}^{2}$, Corisco $15 \mathrm{~km}^{2}$, Elobey Grande $2 \mathrm{~km}^{2}$ y Elobey Chico $20 \mathrm{Ha}$. Frente a las Costas Africanas.

- Habitantes: En todos los territorios, en el año 1936, habia una población aproximada de 157.000 habitantes nativos, de los cuales 155.000 correspondian a Río Muni o Continente, y poco más de 2.000 habitantes a Fernando Poo, de los cuales unos 1.500 eran españoles, algunos centenares portugueses y el resto alemanes e ingleses. Fernando Poo, por ser una isla montañosa con alturas superiores a los 3.000 metros, su clima ecuatorial se modificaba convirtiẻndose en un "sanatorio" y lugar de recreo de los europeos.

- Distancla de España en línea recta: Fernando Poo, la más cercana a $4.200 \mathrm{~km}$, Rio Muni o Continente con Corisco, Elobey Grande y Elobey Chico, $4.500 \mathrm{~km}$. y Annobón, la más alejada, $4.800 \mathrm{~km}$; asi se explica la falta de noticias y conocimientos de lo que ocurría en la metrópolis.

- Lenguas: Habia cierta unidad en Fernando Poo, pero en el Continente existían multitud de lenguas y dialectos; el español lo hablaba el $44 \%$ de los nativos, mientras que estaban bautizados el 85\%; España, en el período 1932-35, importaba de Guinea unos 42.000 millones de pesetas-oro, y exportaba solamente 4.000 .

\section{BIBLIOGRAFÍA}

- Dirección Ciriaco Pérez Bustamante, redacción Joaquín Arrarás: Historia de la Cruzada Española. Volumen VI, Tomo XVI. Pág. 336-366. Madrid, 1941. VV.AA.

- VV. AA., "España en África. Un siglo de fracaso colonial". Historia 16. Extra n. ${ }^{\circ} \mathrm{IX}$. Abril, 1979. 130 páginas.

- LÓPEZ DE GARCÍA, B.: Seis siglos en Africa. Pág. 5-8.

- FERNÁNDEZ CLEMENTE, E.: Un lugar al sol. Colonialismo en Guinea (18831936), pp. 96-104.

- NDONGO-BIDYOGO, D.: Una merienda de blancos. Descolonización de Guinea (1936-1968), pp. 105-116. 
GUINEA ESPAÑOLA

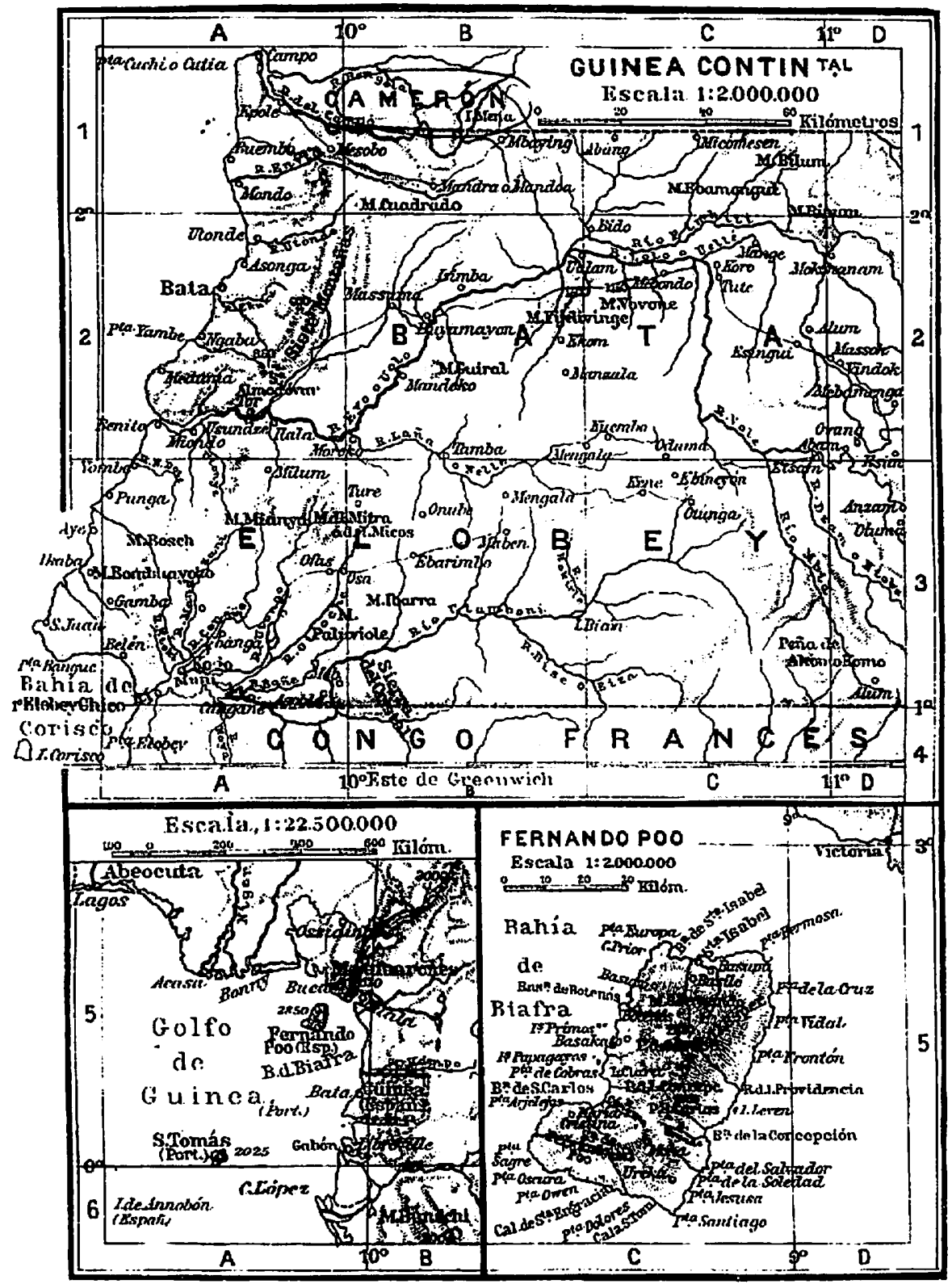




\section{DOCUMENTO 1}

Proceso 28/1. Informe número dos de los políticos y sociales y Fernando Poo - 31 Agosto de 1936. Arquivo do Ministeri dos Negocios Estrangeiros. Lisboa Maço A8M2.

El 14 de Agosto fondeó de nuevo en este puerto de Santa Isabel el crucero español "Méndez Núñez, habiendo desistido de su viaje a España, llegando hasta Dakar.

Se sabe que su regreso fue motivado por el Comandante y oficiales superiores del mismo barco de guerra, que eran partidarios del Movimiento del General Franco y el Gobierno de Madrid no tener confianza por la actitud del barco, ordenó su regreso para aquí.

Con la permanencia aquí de dicho navío, se reanimaron los ánimos de los núcleos del Frente Popular (de Fernando Poo) que comenzaron después a inquietarse.

A su regreso del continente (Río Muni o Guinea) e Isla de Anno Bon, se dirigió una carta al Gobernador General que la consideró inconveniente e irreverente, castigando al presidente del Grupo del Frente Popular, su autor, con una multa disciplinaria de quinientas pesetas.

Como las condiciones financieras de éste fueses precarias, se le embargaron algunos de sus bienes, retirados de su establecimiento, cuya venta de subasta judicial financiada para el $25 \mathrm{del}$ mes corriente. Como no tuvo compradores se anunció una segunda subasta.

Entretanto se soliviantaba el citado grupo político, animado con la presencia del barco de guerra, cuyos marineros y oficiales subalternos estaban de acuerdo con ellos; en tierra, por todas partes de la ciudad, en los bares, en las calles, con la tolerancia del Gobernador General en cuanto el pueblo se alarmaba de posibles graves acontecimientos; no obstante la tripulación, alegan que no les importaba los asuntos de la colonia, pero sí los de España, para donde insistían enérgicamente en ir, en cuanto el comandante estaba gravemente enfermo, durante varios días, a bordo del barco.

De Madrid, no cesaban nuevas instrucciones para que el navio siguiese inmediatamente a la Península, hasta que en virtud de los diferentes sentimientos políticos de su tripulación, el Sr. Gobernador General, que sabe ejercer su cargo con imparcialidad politica, dirigióse la noche del jueves 27 y después de hablar con la oficialidad, mandó formar toda la tripulación, a la que habló, sugiriendo a todos la idea de ir a la Península por la Patria amenazada y que si por ventura existían a bordo elementos contrarios a la política del gobierno Central, convenía que éstos se declararan para que fuesen desembarcados y destituidos de sus cargos.

Este discurso que produjo excelente efecto en todos, calmó el ánimo de los marineros, resultando del mismo que en la mañana del día siguiente fueron desembarcados diez y siete oficiales superiores, incluyendo al Comandante, que acto seguido fueron transportados para la villa de San Carlos, que dista de esta capital unos cincuenta kilómetros por carretera, donde fueron acogidos y hospedados en una casa particular.

Pero entre los que quedaban a bordo, no había nadie para tomar cuenta del barco y conducirlo a la Península, lo que obligó a nuevas intervenciones del Gobernador General para que un Teniente de marina, señalado por los marineros quedara a bordo, sacrificándose por la patria, por los compañeros y por la Colonia, amenazada de ser bombardeada. 
Este brioso militar bastante contrariado, después de reflexionar, dijo estar dispuesto a sacrificar su vida quedando con ellos, haciendo muestra una vez más de su patriotismo.

En la media noche del sábado, abrumado por el paso dado y arrepintiéndose, se dice que intentó suicidarse, a lo que se opusieron los marineros, garantizándole que nada malo le pasaría; después de varias diligencias del Gobernador General, que recelaba por la presencia del navio por causa de los movimientos y combinaciones de los grupos políticos en tierra que contaban con la marinería, fue señalada la salida del puerto, del crucero para el domingo 39 (Agosto) a las dos de la tarde.

Además, el sábado pensaron los marineros, que su intención inmediata ir a bombardear las Palmas, que entre los oficiales que se quedaban o fueran desembarcados, estaba el mejor artillero del barco, cuyo servicios consideraban imprescindibles. En ese sentido hicieron nuevas tentativas junto al Gobernador General, el cual telefoneó al Delegado del Gobierno en la villa de San Carlos, en el sentido de que el of icial indicado embarcase en una lancha inmediatamente para Santa Isabel y se incorporara al barco, siguiendo con ellos el viaje a España, el domingo por la tarde.

De San Carlos, informaban después que la lancha en que el referido oficial habia embarcado para Santa Isabel, habia dejado el puerto en la madrugada del domingo. Y eran casi las cuatro de la tarde, cuando aún no había llegado aquí, haciéndose esta travesía normalmente en cuatro horas.

Fue mandada una lancha de un ciudadano portugués, Antunes, a buscarlo por todos los puntos del camino hasta llegar a San Carlos y habiendo cumplido la misión encomendada, hasta el punto de dirigirse a la casa donde estaban los restantes oficiales, con lo cual les dijo, que había hablado; sin recibir noticia alguna de la lancha que buscaban y tampoco del oficial de referencia, que realmente había salido en la madrugada de ese día en la lancha; entre tanto estaban cortados los servicios telefónicos entre San Carlos y Santa Isabel.

A las cuatro de la tarde, salia del puerto el crucero Méndez Núñez, en medio de una ansiedad pública, esperando encontrarse por el camino, cuya dirección era la de su ruta, el imprescindible oficial para sus hazañas en las Palmas.

Después de la salida del barco, divulgóse por la ciudad que los individuos del grupo "Frente Popular" y sus afiliados, contando con la presencia del barco y del apoyo de la marinería, pretendían asesinar a algunos individuos, entre ellos al Obispo y al Secretario General, quemar la magnífica Iglesia Catedral, la Misión Católica, el edificio del Tribunal de Justicia y el Registro de la Propiedad, etc, etc... a lo que enérgicamente se opuso el Gobernador General, en conferencia con los cabecillas del referido grupo y del marinero Sierra, Jefe de los comunistas a bordo del crucero.

Santa Isabel de Fernando Póo. 31 agosto de 1936. El Vicecónsul interino. Por el bien de la Nación. Fdo. Juan Ramírez de Dampierre. 


\section{DOCUMENTO N. 2}

URGENTE. CONFIDENCIAL. $N^{0}$ 19. Santa Isabel. 10 Sept. de 1936. Sr. Ministro de Negocios Extranjeros [...] "Protección a la colonia portuguesa".

Los movimientos que hace cerca de dos meses se vienen desarrollando en España, han tenido repercusión en los ánimos de los que aquí residen, donde han aparecido movimientos subversivos que sólo la energía implacable y la imparcialidad del digno Gobernador General local, ha sabido imponerse evitando asi desgracias entre el grupo llamado, "Frente Popular" y los que condenando los principios comunistas y los actos de exterminio que desde hace meses se practican en la Península y apoyan a los nacionalistas, los cuales constituyen la mayoria de la colonia, no obstante se mantienen pacificos y casi ignorados.

Varias veces estuvo a punto de producirse hechos sangrientos, como a fines del mes pasado, durante los últimos días de estancia en el puerto del crucero Méndez Núñez, que tuvo que enviarse a la Peninsula, por motivo de que la tripulación estaba unida al grupo del Frente Popular local, después que la oficialidad en número de 17 hombres, desembarcó por ser contrario al Gobierno Central.

Por estas circunstancias y por otras razones imposibles de describir, los ánimos de todos y principalmente de los extranjeros están desesperados porque dada la hipótesis del Gobierno de Madrid de vencer esta contienda, se espera tengan lugar aquí los actos lamentables y sangrientos.

Cumpliéndose sete consulado, el deber de exponer al Gobierno que representa, el hecho de la gravedad del momento actual tal como se presenta, transmite la idea de algunos portugueses de solicitar la venida de un navio de guerra de su país, para protección de la numerosa colonia portuguesa aquí residente, en su mayoría compuesta de agricultores y comerciantes, sobre los cuales pesa la indignación de los revoltosos en virtud de la actitud de Portugal en la contienda, limitándose una vez más a rogar a V. E. se digne considerar debidamente el asunto, adoptando las providencias que el alto criterio y esclarecida inteligencia de $\mathrm{V}^{\mathrm{a}} \mathrm{Ex}^{\mathrm{a}}$ aconseje. Por el bien de la Nación. El Cónsul interino. Juan Ramírez Dampierre.

\section{DOCUMENTO $\mathrm{N}^{\circ}$ 3. (Informe $\mathrm{n}^{0} 21$ ) "Gravísimos acontecimien- tos políticos que implican la protección de la Colonia portuguesa. Santa Isabel 23 de Sept. de 1936.}

Excmo. Señor: tengo el honor de confirmar, el contenido del oficio $n^{*} 19$ de este consulado de 10 de septiembre corriente, por equivocación numerado 13 .

Confirmo igualmente el radiograma expedido por este consulado en 21 del mes corriente, cuyo contenido es: "Teniendo grandes disturbios, próxima llegada barco español procedente de Barcelona, necesitando protección numerosa colonia de esta Isla, ruego envie urgente, barco de guerra. Vicecónsul".

Conforme se preveía en aquella fecha, gravisimos acontecimientos se proyectaban desenvolver en esta colonia, repercutiendo aquí, los actos políticos y sociales de España, donde un grupo del Frente Popular se propuso ejercer su acción extremista, en virtud de los 
cual, providencialmente, sus planes se vieron frustrados, con el violento golpe de Estado de los Nacionalistas el 19 del corriente, desde cuyo momento, la Colonia pasó a la política redentora del brioso General Franco.

Por el relatorio número 13 de esta fecha enviado al Excmo. Sr. Embajador de Portugal en Madrid y que va junto a este oficio, se enterará de los acontecimientos gravísimos que todavía se aproximan con la llegada aquí, sobre el día 28, del barco español procedente de la Península con 300 comunistas abordo, armados y equipados de ametralladoras, para hacer aquí las mismas hazañas destructoras que hace meses ensangrentaron el suelo español.

En virtud de la alarma natural que tales noticias causaron en los ánimos del público de la numerosa colonia portuguesa como de todas las demás extranjeras, pretende saber qué providencias se han adoptado por el Gobierno Central con respecto al radiograma arriba indicado; preocupado, porque han pasado tres dias y no se ha tenido noticias de su recibo, y faltan apenas seis días para dichos acontecimientos.

Al pedirse el barco de guerra, se esperaba aquí que el Gobierno mandaría destacar uno de los barcos que en Angola están habitualmente.

Sea como fuere el consulado y la colonia portuguesa confian plenamente en el patriotismo y solicitud del Gobierno. Sr. M.N.E. Por el bien de la Nación. Fdo. Juan Ramírez de Dampierre. (Nota. Este oficia y relatorio se enviará aprovechando la salida para las Palmas de un barco frutero alemán que regresa a Hamburgo.

\section{DOCUMENTO $\mathrm{N}^{\circ}$ 4. Informe Anexo no 3. Sucesos políticos y sociales de Fernando Póo.}

El día 6 de Septiembre, llegó la lancha que se esperaba el día 30 de San Carlos, con el oficial artillero, procedente de Victoria en el Camerún inglés. Interrogado por la policía gubernativa su tripulación declaró ésta que el pasajero de referencia que se habian de traer de San Carlos, al llegar frente la bahía de esta capital, amenazó con una pistola a que siguiesen viaje para el continente, desembarcando cerca de Victoria donde se quedó.

El dia 4, aún sin saber nada de esta lancha, salía de la bahía para el mismo puerto, San Carlos, otra, capitaneada por el ciudadano portugués Eugenio Pereira Antunes, en su viaje comercial habitual, entre los dos puntos, de bien de regresar por la tarde del día siguiente, sábado. Súpose después que en la mañana del día siguiente dicha lancha habia salido de la bahia de San Carlos, sin embarcar a los pasajeros y carga habitual en la noche anterior, sino llevando los 12 oficiales del Crucero Méndez Núñez, incluyendo el Comandante, el Delegado del Gobierno de San Carlos, el importante agricultor español que había hospedado en su roca (sic) a los oficiales y a dos particulares. Al mismo tiempo se interrumpian las comunicaciones telegráficas entre los dos puntos. Por último el dia 7 (Septiembre), cerca de la una de la tarde entrada en el puerto de Santa Isabel la referida lancha, regresando de mismo punto, Victoria, en el Camerún inglés.

Preso su capitán y con él, la tripulación y cuatro soldados indígenas armados, fueron todos llevados a la Policía Gubernativa para interrogarlos. Allí declaró el Capitán Antunes, que están durmiendo en San Carlos, en la casa que se hospedaban; aparecieron alli en la 
noche del viernes, los cuatro soldados indigenas de la guardia colonial, armados de fusiles, intimidándoles a acompañarles de Orden del Delegado del Gobierno. Obligado asi a obedecer, fue conducido a la playa donde estaba su lancha y donde se encontraban todos los individuos arriba citados y toda la tripulación a bordo, obligándole el Delegado a subir y salir inmediatamente amenazándoles con pistolas.

Puestos a bordo, tomaron la dirección de Santa Isabel, mas al aproximarse a la bahia de esta capital, lo obligaron a cambiar de rumbo a Victoria, lo que no pudo dejar de hacer, tanto más que los cuatro soldados indigenas estaban encargados de hacer fuego a cualquier embarcación que les saliera al paso en la bahía en dirección a Victoria.

Todos los individuos desembarcaron en Victoria, donde estaba el oficial referido y que al día siguiente intentaban tomar a un barco que pasaba por las Palmas para juntarse a los nacionalistas mandados por el General Franco como de hecho se oyó decir después, la noticia de la llegada de todos a aquella Isla.

Estas declaraciones, del capitán portugués que fueron integramente confirmadas por la tripulación y soldados, todos indigenas locales, fueron tomados y acto continuo todos puestos en libertad.

Días después llegaba la noticia del continente español de esta colonia, de que el administrador territorial de Ebebeyin (administrador de la circunscripción) había abandonado su puesto y emigrado al territorio francés limítrofe del Camerún, para seguir viaje y juntarse también a los nacionalistas, llevando consigo el cofre de los fondos del Estado bajo su guardia, el cual entregó al Gobernador de aquella colonia; para que fuese enviado oficialmente al Gobierno General, declarando que llevó consigo aquellos valores para librarse de la responsabilidad de lo que les podia pasar después de su ausencia, con tantos comunistas existentes en esos territorios, y sobre todo en Bata, como se sabe.

El dia 16 (septiembre) aproximadamente llegó un radio del Gobierno de Madrid, para el Gobernador General Local, aceptándole la dimisión pedida al cambiar de Gobierno el país y recomendarle entregar el Gobierno de la Colonia a un individuo competente y del color político del gobierno de Madrid, al mismo tiempo que le aconsejaba embarcar, marchándose de la Isla en el primer transporte que se le ofreciera para su seguridad personal o después de varias tentativas del mismo siempre opuesta a la opinión pública nacionalista que en esta isla constituye la enorme mayoria, además de tener todo el regimiento y la Policia gubernativa a su lado y sobre todo por la actitud del Gobernador General en escoger la persona a quien confiar el Gobierno, y sobre todo por andar amigablemente con los elementos principales del Grupo del Frente Popular local, fue dado un "golpe de Estado", en la madrugada del sábado 19 del corriente (septiembre); reteniendo con respeto al Gobernador General que continúa ocupando su casa particular en el Palacio, detenido e incomunicado, esa mañana desde las seis, fueron hechos presos cuantos constituian el Grupo Político Frente Popular y sus simpatizantes, siendo las prisiones hechas por milicias nacionalistas, acompañadas cada una de tres soldados de la Guardia Colonial indigena, todos debidamente armados y equipados. Todo Esto ocurrió con el mayor orden y serenidad, alterado tan sólo con el paso constante de camionetas con tropas armadas en los puntos estratégicos de la ciudad e iban a las casas de los individuos que iban a hacer prisioneros; sólo ha sido herido un extremista por 
haber disparado una pistola dos veces al intentar huir cuando en su casa le dieron la voz de alto, el cual se encuentra hospitalizado.

Sobre las 8 de la mañana del mismo día 19 , fue izada la bandera nacional antigua en medio de gran solemnidad y concurrencia del pueblo que la aclamaba, con la guardia de honor hecha por el regimiento local de la Guardia Colonial, cuya banda tocó el himno de Riego, izándose la bandera primeramente en el edificio del Consejo de Vecinos (Ayuntamiento) y después con la misma solemnidad en el Palacio del Gobierno General de la Colonia, seguido de grandes aplausos de la multitud. Entretanto, había asumido el Gobierno General de la Colonia, el Jefe de la Guardia Colonial, que ya era Comandante Militar de la ciudad, y hacía tiempo estaba en estado de sitio, fijándose enseguida, el bando cuyo ejemplar se adjunta.

Después se decía que el movimiento nacionalista tuvo lugar esa madrugada para frustrar el movimiento sangriento que los adversarios pensaban dar en la madrugada del domingo, pero de forma terrible y asesinando a varios individuos.

Al ser detenido y depuesto el gobernador General, facilitó al Gobernador Militar su sustituto, un radio que dias antes había recibido del Gobierno Central de Madrid en cifra, en el que se le anunciaba que en el barco español Fernando Poo, de camino para esa Colonia y esperando aquí cerca del 28 de este mes, habían embarcado en el puesto de Málaga varios individuos comunistas y extremistas en gran número que algunos dicen de 300 , debidamente armados y con ametralladoras, para ir a ocupar esa Colonia, asesinado al Gobernador General y a varias autoridades e individuos de color político contrario, pensando así realizar aquí las hazañas acostumbrados en España, previendose gravisimos acontecimientos, a la llegada del referido barco, cuya tripulación es también toda comunista. Es esta conformidad las autoridades locales están tomando las providencias necesarias que loas gravísimas circunstancias suponen para hacer frente a tales extremistas y comunistas.

Dada la alarma general del pueblo, asombrado de los acontecimientos sangrientos que van a desarrollarse aquí, los súbditos locales de varios países extranjeros, se han presentado a los representantes de sus países respectivos o consulados solicitando las soluciones que el caso requiere. Por este hecho el Cónsul de Inglaterra pidió a su Gobierno el envío inmediato de un barco de guerra para la protección de sus súbditos; consta que el Consulado alemán tomó idénticas providencias y este consulado de Portugal, cuya Colonia es la más numerosa y al cual todos los ciudadanos portugueses se dirigen continuamente, alarmados, ya hace días, por este motivo se vio obligado a telegrafiar al digno Excmo. Señor Ministro de Negocios Extranjeros en Lisboa, exponiendo la grave situación, pidiendo el envío de un navío de guerra, esperando sean dadas instrucciones al Gobierno General de Angola para que se envie aqui alguno de los barcos habitualmente estacionados en aquellos puertos, pues no se puede esperar que tal barco venga de Portugal. Hasta este momento se espera con ansiedad las providencias adoptadas por el Gobierno Central; en cuanto el Consulado inglés cuyo radio salio junto, hace tres días que ya tiene respuesta.

Después de las prisiones efectuadas y como el caso lo aconsejaba se hicieron registros en los domicilios de los presos, habiéndose encontrado gran número de armamento diverso, así como documentos importantísimos de los proyectos extremistas del Grupo del Frente Popular. 
También se encontraron manifiestos comunistas venidos de España y otros varios articulos para sus fines extremistas, recientemente recibidos de un barco venido de España y llegado aqui al principio del mes corriente; además se esperaba que trajera medicamentos que tanto hacen falta aquí, cuando al final tan sólo trajo unas pocas cajas de "medicamentos", para el Hospital, quinina la mayor parte, algunas sacas con impresos anteriores al 18 de julio y nada más, ni carga ni tampoco pasajero alguno.

Se sabe que el grupo preso, pretendía asesinar al Gobernador General, al Obispo y a varias entidades oficiales y a todos los agricultores y comerciantes de categoría, españoles y extranjeros, en total unas sesenta personas, entre ellos diez y siete portugueses. Las esposas de las víctimas serian distribuidas entre ellos (solteros), conforme lista encontraba. También se sabe que entre los extremistas hay tres portugueses, "porque portugueses malos, siempre los hubo"; el Consulado está interesado en saber quienes son para tomar providencias enérgicas, adoptando incluso su expulsión inmediata, si anles no sufren las consecuencias de sus compañeros presos, sin poder contar con la protección consular.

La correspondencia procedente de Europa y concretamente la de Porlugal, aquí llega por el vapor inglés "Acalabar" y el alemán WAGOGO; la semana pasada vinieron ambos, el último, llevando más de cuarenta sacas, una excepción de la procedente de Nigeria, destinada a los indigenas de esa colonia en "rocas" locales y algunos impresos comerciales sin importancia, toda ella fue quemada en Correos.

Ya hace días el periódico bisemanal local "El Defensor de Guima", se subleva contra las noticias que del movimiento político de España, daba el gran diario de Lisboa "O Semto", insinuando que ese periódico y algunos otros extranjeros y más tarde el "YA", nacionalista, no debian permitirse circular en la Colonia. Parece que la quema se hizo con consentimiento del Gobernador General depuesto, aunque se duda.

Los presos políticos en número de cuarenta, están bien guardados y vigilados por las milicias, como también bien tratados, pudiendo recibir de sus casas o pensión las comidas y todo lo que necesiten para su uso personal, pero sin comunicación con el exterior del enorme barracón de cemento, donde se encuentran muy bien instalados bajo rigurosa vigilancia. Entre ellos hay media docena de funcionarios de la Secretaria General del Gobierno, cuatro de la Administración de Hacienda, tras de la Administración de Correos, incluyendo el propio Administrador y varios particulares, algunos sin importancia, además de dos negros. También el capitán del Puerto se encuentra entre ellos, señalado como Gobernador Central comunista.

Comunicado al continente español, el "Golpe de Estado", dado en la capital de la Colonia, Sta. Isabel, en Fernando Póo, en Bata, capital del continente, donde la mayoría de los europeos son comunistas, no se adhirió, suponiéndose que las cosas alli pueden haber tomado sentido contrario, tanto más cuando del Kogo y Río Benito, respondieron aquí, que se adherian y que marcharian sobre Bata, donde la sargentada estaba compuesta por los comunistas locales que son numerosos.

Al conferirse los valores postales, se supo que existia en el cofre de Correos doscientas mil pesetas, de giros postales hechos por el público para los dos últimos vapores nacionales que cada mes salen para Europa, sin que tal transferencia se hiciera por los oficiales; 
tampoco los fondos depositados en el Banco Exterior de España, como debía haberse hecho; la llave del cofre ha sido entregada después de mucho trabajo por la esposa del administrador respectivo, también preso. Santa Isabel 23 de septiembre de 1936. Por el bien de la Nación. Fdo. Juan Ramírez Dampierre.

\section{DOCUMENTO $\mathrm{N}^{\circ} 5$}

Luis de Sampaio, escribe al Jefe del Gabinete de su excelencia, el Ministro de Marina, con fecha 30 de septiembre, las noticias que vienen de Guinea Española a través del Vincecónsul y el telegrama recibido en Lisboa, el día 21 de septiembre.

\section{DOCUMENTO $\mathrm{N}^{\circ}$ 6. OFICIO $\mathrm{N}^{\circ}$ 818. Ministerio de marina. Excmo. Señor Secretario General del Ministerio dos Negocios Estrangeiros.}

En referencia a su oficio $\mathrm{n}^{\circ} 38$, jueves $28 / 1$ de septiembre pasado, me encargó su Excelencia el Ministro de Marina de comunicarle que en Santo Tomé a 230 a 230 millas de Fernando Poo, está la cañonera Ibo, que puede en caso de necesidad ir a aquella Isla, pero se piensa que su valor militar es muy pequeño. También me encarga el mismo Excmo. Señor, de comunicarle que fue dada orden de que siguiera a las colonias, uno de los nuevos "avisos", que hacen escala en Cabo Verde y Guinea, pero en virtud de la situación en Fernando Póo, esta última escala puede ser suprimida. Por el bien de la Nación. Repartiçao do Gabinete 6 octubre de 1936. El Jefe del Gabinete Américo Deus Rodríguez Tomaz. Capitán-Teniente Fdo.

\section{DOCUMENTO $\mathbf{N}^{0}$ 7. Telegrama $\mathrm{n}^{\circ} 13$.}

Ruego diga si se confirma los recelos de sus últimos telegramas y sus fundamentos. Ministro.

\section{DOCUMENTO $\mathbf{N}^{\circ} 8$. Informe $\mathrm{n}^{\circ} 23$.}

Santa Isabel 19 octubre 1936. Como la situación estuviera dudosa (el día 11), no fue posible responderle en aquel momento, al mismo tiempo que se contaba con una anormalidad política local; por eso solamente hoy, puedo responderle de la forma siguiente: Situación normalizada. Vicecónsul.

(Incluido mismo documento). Por el informe $\mathrm{n}^{\circ} 4$ (adjunto) destinado al Excmo. Señor Embajador de Portugal en Madrid y que envió por medio de ese Ministerio, se enterará de los sucesos locales y de los fundamentos de los recelos presentados en los radios de referencia, que felizmente y providencialmente pasaron. Por el bien de la Nación. Fdo. El Vicecónsul. Fdo. Juan Ramírez Dampierre. 


\section{DOCUMENTO $N^{\circ} 7$. Anexo. Informe n" 4.18 octubre de 1936... Se confirman los contenidos de los tres informes anteriores.}

Los grupos socialistas y comunistas del Continente Español, continúan dueños de la situación política allí, habiendo detenido al Gobernador del Distrito, a los sacerdotes y religiosos, ejerciendo algunos actos violentos, que ocasionaron la fuga de los europeos contrarios, que en virtud de la situación se han visto obligados a tomar varios barcos para ir a Santa Isabel, procedentes de varios puntos de las colonias extranjeras limítrofes, donde se han refugiado.

Consta que alli se ejercieron represalias y pillajcría a los bienes de los refugiados, algunos extranjeros. El vapor español Fernando Póo, que tanta alarma provocó su esperada llegada, procedente de España; al saberse a bordo que había cambiado la situación política local, se refiere a Fernando Póo, siguió directo a Bala, capital del Continente español, en vez de tocar aqui primero como de costumbre, donde se estacionó algún tiempo, sin efectuar descarga ni desembarques, según cuentan los refugiados, aguardando el final de los acontecimientos políticos del país $\mathrm{c}$ instrucciones del Gobicrno Central.

Entretanto faltaba toda clase de viveres en la isla, que nada más produce cacao, café y bananas.

De las Palmas, nada se exportaba porque la colonia era adicta a la política de Madrid y de la Península nada venía por falta de transportes y por hacer falta allí todo.

Algunos géneros de alimentación para curopeos que entraban en esta isla, procedían de Duala, Camerún francés, de donde sc consiguió la adquisición más o menos regular a cambio de cacao local, para evitar la salida de fondos al extranjero y porque a aquella colonia francesa convenía importar cacao de Fernando Póo, que dicen, ser superior al que ella produce.

Sobre Bata, fueron lanzados por un avión, dias después, algunos bandos del Gobierno General de la Colonia de fecha 19 de septiembre y algunos ejemplares del nuevo periódico "El Nacionalista", sin producir los resultados esperados.

El número de presos políticos o sospechosos, continúa creciendo y algunos que habian sido puestos en libertad, poco después, por considerarlos inofensivos, fueron de nuevo capturados al hacerse nuevos registros en sus domicilios o por haber nuevas denuncias contra ellos. Procedente de las Palmas se espera aquí del 13 al 14 del corriente, la llegada de un vapor con tropas y armamentos para someter todo cl continente español y mantener el orden en toda la Colonia de Guinea Española.

La fiesta de la raza, del día 12 (octubre), fue celebrada aquí con todo esplendor, habiendo misa de campaña rezada por el obispo, cambio de la bandera del Regimiento Colonial por otra ofrecida por las Milicias Nacionalistas, previamente bendecidas por el Obispo y varios desfiles de las Milicias y de la tropa indigena, con Sanda, por algunas de las principales calles de la ciudad, cuyo número va creciendo con los refugiados del continente, además de voluntarios, como de las tropas indígenas y por algunos voluntarios y nuevos reclutas contratados. 
Todas estas fiestas se vieron realzadas por la gran asistencia dele elemento indígena, alegre y satisfecha por la conclusión del asunto y el regreso a las instituciones antiguas.

El mismo día 12, se recibía en este consulado un radiograma del Ministerio de Negocios Extranjeros de Lisboa, con referencia a los radiogramas expedidos el 21 y 24 de septiembre pasado, solicitando el envío de un barco de guerra para proteger a la numerosa colonia portuguesa, en el caso de que ocurrieran casos sangrientos, previstos con la venida del vapor español Fernando Póo, donde se preguntaba, si persistian los recelos y cuales eran sus fundamentos.

Durante los dias de mayor ansiedad en esta Colonia, estuvo fondeado en el puerto de Santa Isabel, un vapor alemán, el Wagogo, regresado de los puertos del Sur (de España) y trayendo refugiados españoles y alemanes frecuentemente este puerto ha sido visitado por varios barcos mercantes o fruteros de aquella nacionalidad. El vapor frutero alemán "Pontos", estuvo a las órdenes del Consulado alemán, durante los días 8 al 13 de este mes (octubre), habiendo llevado al cónsul alemán, al Continente Español, en visita a sus conciudadanos allí establecidos e informarse de su situación y sus bienes, regresando después.

También el vapor Costero inglés "Calabar", hace escala en ésta, todas las semanas, pudiendo, todavía, la colonia británica, obtener otro barco, de un momento a otro, de la Nigeria próxima, en caso de ser requerido por su consulado.

Día 15. Cerca de mediodía corría con insistencia por la ciudad, de que el barco español esperado en las Palmas, había radiografiado desde Bata, habiendo tomado el Continente español, hundido al vapor comunista Fernando Póo, allí refugiado y debiendo llegar a Santa Isabel, por la mañana.

Día 16. Efectivamente a las dos de la mañana, se avistaba el vaporcito "Ciudad de Mahón" de regreso de Bata, la ciudad se vistió de fiesta al toque de diana, por las milicias en las principales calles y puntos de la ciudad, apareciendo balcones y ventanas engalanadas de banderas. Los edificios públicos y los consulados con sus banderas.

La multitud en masa, corría por la Plaza de España, cercana al mar, la Cuesta de la Marina y la Explanada del puerto, en cuyo muelle la aglomeración del pueblo era inmensa y enorme el movimiento de coches.

Después de llegar el barco y efectuadas las maniobras de atraque, el vaporcito atracó al espigón del muelle, encontrándose ya allí el Gobernador Militar, todas las autoridades y todo el elemento europeo, los refugiados del Continente, así como las Milicias Nacionalistas formadas con sus bandas.

Tocose entonces, el himno de Riego, que desde a bordo del Ciudad de Mahón, el Comandante de la tropa, hizo sustituir por el himno de Falange española, cantado a coro por la tropa y marinería de abordo y por las Milicias en tierra, después de lo cual, salió de a bordo, un viva a Franco, estruendosamente correspondido por la enorme masa del pueblo, seguido del saludo fascista. Se efectuó después el desembarque de los heridos procedentes de Bata, para el coche ambulancia del Hospital Central, donde fueron alujados.

El vaporcito "Ciudad de Mahón", de unas 1500 toneladas y que fue construido recientemente al abrigo del contrato entre el Estado y la Compañia Transmediterránea y que 
se destinaba, al servicio de cabotaje de esta Colonia, donde era esperado hace más de un año para hacer su servicio. Cuando venía de las Palmas para este puerto captó algunos radios, cambiados entre el vapor comunista Fernando Póo, en Bata y el Gobierno de Madrid, de los cuales se desprendía que dicho vapor debía dejar Bata, en breve, e ir a España.

Por este hecho, se resolvió a bordo, que el "Ciudad de Mahón", siguiese directo a Bata, antes de escalar esta isla, ya por tener elementos conocedores de la Colonia a bordo, como tropa y armamento suficiente para todo lo que fuera necesario. Habiendo pasado a la vista de esta capital, a mediodía del martes 13 y llegado a Bata en la madrugada del 14, enarbolando bandera francesa, con gran regocijo de los comunistas de Bata.

Momentos después, sustituye la bandera francesa y enarbola la española y dispara una pieza de artillería para intimidar al vapor Fernando Póo a rendirse. Éste que habia izado la bandera blanca, al aproximarse a bordo las embarcaciones enviadas desde el vaporcito "Ciudad de Mahón", las recibió a tiros, lo que obligó a éste, a responder con fuego de artillería. En determinado momento el vapor comunista, cuyas anclas estaban izadas y pronto a zarpar, reculaba para tomar posición de atacar al vaporcito, el cual siendo de 600 toneladas brutas (sic), intentó partirlo por medio. En este momento el vaporcito disparó debajo de la línea de agua, produciéndole agujeros que momentos después lo hundió. El vaporcito traía dos piezas de artillería montadas, tropa diversa, en total de 700 hombres y armamento abundante, moderno, de toda clase, con personal especializado.

Entre la tropa venían también 300 soldados moros, 200 de los cuales, quedaron en Bata para mantener el orden y perseguir a los refugiados hasta las fronteras limitrofes. De Bata, se trajeron cincuenta prisioneros, la mayor parte marineros del Fernando Póo, cogidos en el mar. Sobre las nueve de la mañana se hizo el desembarco de la tropa, que quedó acuartelada en diversos edificios de la ciudad, divididas por su especialidad y seguimientos. La ciudad tomó entonces un movimiento sorprendente, con el gran movimiento de tropas y camiones, tanto del Estado como de particulares, todos puestos a disposición del Gobierno Militar y de la tropa de desembarque para todos los servicios necesarios, especialmente en la conducción de equipajes y armamentos diversos del barco, como de paseos más tarde de las tropas, por las calles de la ciudad y carreteras de las Islas.

Los gritos de viva Franco y Arriba España durante todo el día y noche de este primer día, no cesaron, tomando la ciudad el aspecto de una plaza militar, recientemente conquistada por el ejército Salvador del glorioso General Franco y sus briosos compañeros.

La animación es general por la ciudad, el entusiasmo grande y la alegría de todos, cuyos rostros manifiestan satisfacción sin distinción, europeos, indigenas, españoles y extranjeros.

El comercio, incluso el pequeño, cerró sus puertas durante todo el día 16, espontáneamente, pues quien no tuvo tiempo de abrir antes de la llegada del barco no abrio por la tarde del mismo dia, asociándose a los recién llegados y ansiosos de abrazar a sus amigos y conocidos antiguos, que se habían refugiado en Las Palmas, durante la crisis política relatada en los informes anteriores y que vinieron ahora, también con la tropa, ansiosos al mismo tiempo por saber de los acontecimientos de Bata. 
Se sabe que el Gobernador del distrito de Bata, que decía estar preso de los comunistas, huyó al Camerún francés, llevando consigo 700.00 pts. De Hacienda y del Banco. Los pasajeros del vapor comunista, parece que habían hecho causa común con la marinería o con los comunistas de Bata, en su mayoría. Toda la carga que estaba a bordo se ha desembarcado en Bata, por cuanto el barco estaba preparado para escapar, aunque durante algunos dias, pensaron atracar a Fernando Póo, antes de seguir a España.

Entre las tropas venidas de España venían algunos marineros de guerra que prestaban sus servicios como tripulantes del barco Ciudad de Mahón, debidamente armados en barco de guerra.

El vaporcito Ciudad de Mahón, vuelve hoy a Bata por la noche, donde va a completar su trabajo, debiendo después traer a los prisioneros, ya hechos y al importante agricultor del Distrito de San Carlos, que en el informe número tres, se dijo había hospedado a los oficiales del crucero Méndez Núñez y que había seguido con ellos a Victoria y Las Palmas y que actualmente se encontraba en Bata como Gobernador interino.

Durante los disparos hechos al vapor Fernando Póo en Bata, fallecieron y resultaron heridos algunos individuos nacionalistas, presos a bordo de los cuales se hizo mención al desembarcar; fallecieron dos sacerdotes sacrificados por los comunistas, un comerciante preso a bordo y cinco voluntarios de las tropas de Las Palmas que al hundirse el barco, el Fernando Póo, estaban registrando los camarotes. Por las almas de estas víctimas, se ofreció una misa hoy de mañana en la Catedral. Por el bien de la Nación. El Vicecónsul interino. Fdo. Juan Ramírez Dampierre. Santa Isabel de Fernando Póo. 19 octubre de 1936.

\section{DOCUMENTO N $^{\circ}$ 9. Telegrama.}

Fernando Póo. 19 de octubre de 1936. Situación normalizada. Fdo. Vicecónsul.

\section{DOCUMENTO No 10. Telegrama 212.}

Londres 26 de octubre de 1936. Embajador de eSpaña en Londres entregó nota al Foreign Office, comunicando barco portugués, "Ciudad de Macau", hundió a tiros, barco español en la Costa de África, creo cerca de Fernando Póo. Ruego a V. Ea. confirmación, a fin de estar habilitado responder pregunta, eventualmente, me sea hecha en el Comité. Fdo. Calheiros.

\section{DOCUMENTO No 11.}

Lisboa 29 octubre. Diga con urgencia si se produjo ahí cualquier incidente algún barco portugués, además de lo referido en sus informes de 23 de septiembre. a) Ministro.

\section{DOCUMENTO Nº 12.}

Fernando Póo. 31 octubre 1936. Ningún incidente. Situación normalizada.

a) Vicecónsul. 


\section{DOCUMENTO $N^{\circ} 13$. (Se refiere a los dos telegramas anteriores).}

Fernando Póo 31 de octubre 1936. Portugal no tiene ningún barco llamado así; tan sólo hay una draga denominada Macau, registrada en Macau. (Respuesta de Lisboa al Embajador en Londres).

\section{DOCUMENTO $\mathbf{N}^{\circ} 14$. Oficio $\mathrm{n}^{\circ} 898$.}

El Ministerio de Marina Américo Deus Rodríguez Tomás, informe al Secretario General del Ministerio de Negocios Extranjeros, sobre el Ciudad de Mahón.

\section{DOCUMENTO N"15.}

Embajada de Portugal en Londres. 26 de noviembre de 1936. Embajador en Londres, Calheiros insiste, sobre los mismo. 

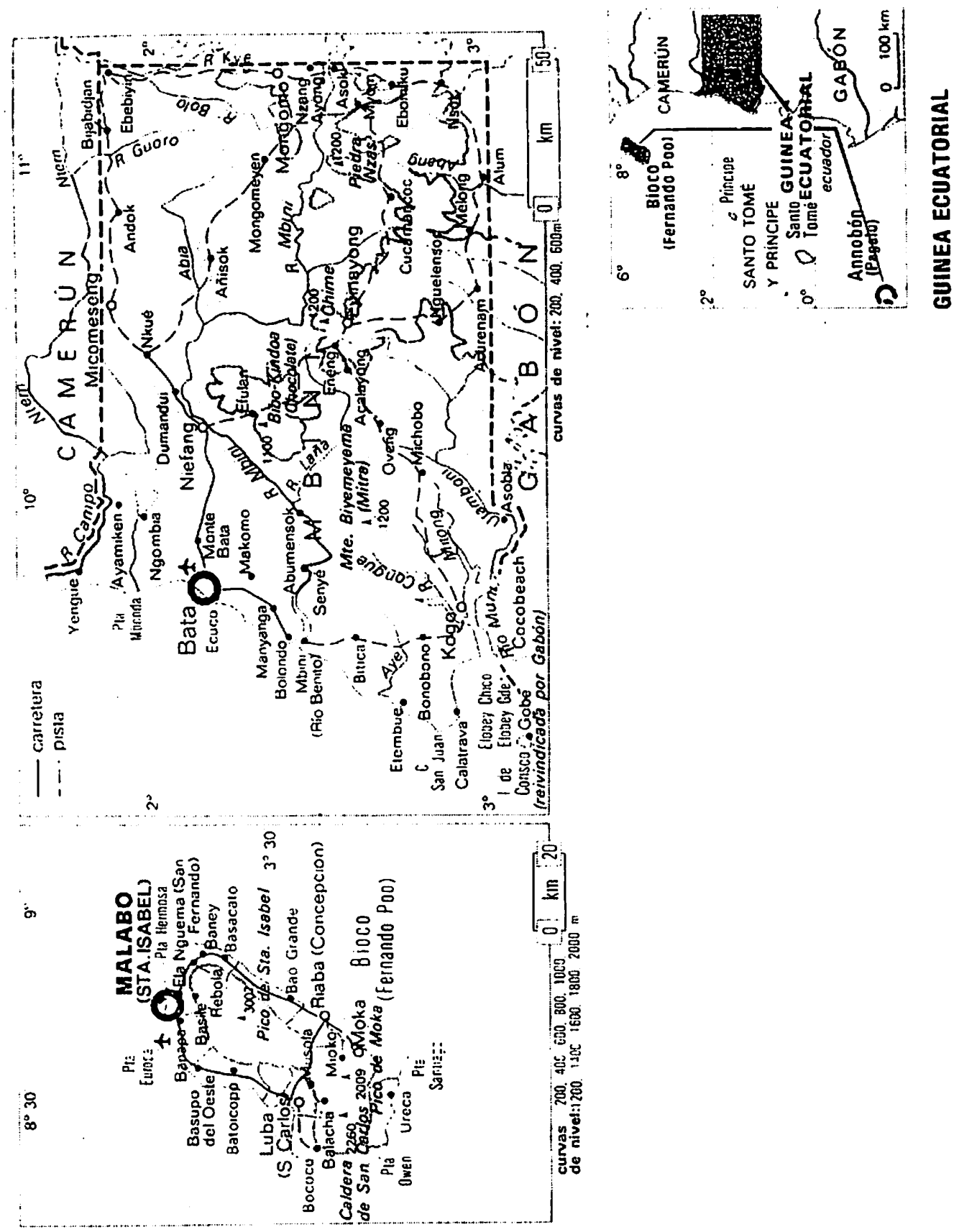